\title{
Risk factors for the progression of unruptured intracranial aneurysms in patients followed by CT/MR angiography
}

\author{
Guang-Xian Wang ${ }^{1 \#}$, Lan-Lan Liu ${ }^{1 \#}$, Yan Yang ${ }^{1}$, Li Wen $^{1}$, Chun-Mei Duan ${ }^{2}$, Jin-Bo Yin ${ }^{3}$, Dong Zhang ${ }^{1}$ \\ ${ }^{1}$ Department of Radiology, Xinqiao Hospital, Third Military Medical University, Chongqing, China; ${ }^{2}$ Department of Neurology, Xinqiao Hospital, \\ Third Military Medical University, Chongqing, China; ${ }^{3}$ Department of Neurosurgery, Xinqiao Hospital, Third Military Medical University, \\ Chongqing, China
}

Contributions: (I) Conception and design: D Zhang; (II) Administrative support: D Zhang; (III) Provision of study materials or patients: CM Duan, JB Yin; (IV) Collection and assembly of data: LL Liu, Y Yang, L Wen; (V) Data analysis and interpretation: GX Wang, LL Liu; (VI) Manuscript writing: All authors; (VII) Final approval of manuscript: All authors.

\#These authors contributed equally to this work.

Correspondence to: Dong Zhang. Department of Radiology, Xinqiao Hospital, Third Military Medical University, Chongqing 400037, China. Email: xqzhangdong@163.com.

Background: The progression of an unruptured intracranial aneurysm (UIA) is associated with a higher rupture risk. The aim of this study was to identify the risk factors for the progression of UIAs among Chinese adults and compare them with the ELAPSS (Earlier subarachnoid hemorrhage, IA Location, Age, Population, IA Size and Shape) score.

Methods: Four hundred thirty-eight consecutive patients with 491 UIAs were followed and reviewed retrospectively from August 2011 to November 2019. Follow-up images of the UIAs were used to determine changes in IA size and shape. Patients and IAs were divided into non-progression and progression groups. In addition to the clinical characteristics of the patients, the features of the IAs (e.g., size and shape) were evaluated by computed tomography angiography (CTA) or magnetic resonance angiography (MRA). Independent risk factors for UIA progression were studied using multiple Cox proportional hazards regression analysis. In addition, the diagnostic value of the ELAPSS score for the prediction of UIA progression was calculated.

Results: Seventy-two IAs in 68 patients progressed during a mean follow-up time of $24.2 \pm 19.68$ months. IAs located at the bifurcation [odds ratio (OR) 2.600], with an irregular shape (OR 2.981) or having a high aspect ratio (AR, OR 2.430) were correlated with progression. Based on these three factors, the threshold value of our predictive score was 0.5 , and the area under the curve (AUC), sensitivity and specificity were $0.756,93.1 \%$ and $40.6 \%$, respectively, while the AUC, sensitivity and specificity of the ELAPSS score were $0.711,55.6 \%$, and $75.2 \%$, respectively.

Conclusions: IAs located at the bifurcation, with an irregular shape and with an elevated AR are risk factors for UIA progression in the Chinese population. Our predictive score is of great value in predicting the risk of UIA progression.

Keywords: Intracranial aneurysms; risk factors; aneurysm progression; China

Submitted Jan 08, 2021. Accepted for publication Apr 13, 2021.

doi: $10.21037 /$ qims-21-32

View this article at: http://dx.doi.org/10.21037/qims-21-32 


\section{Introduction}

The number of incidental unruptured intracranial aneurysm (UIA) diagnoses has increased due to the increased use of noninvasive vascular neuroimaging. Although the rupture risk of UIAs is very low; when an IA ruptures, the mortality and morbidity rates are still high (1). Furthermore, prophylactic treatment of all UIAs is not practical and is also associated with risks of complications. Hence, many UIAs are left untreated and are followed via computed tomography angiography (CTA) or magnetic resonance angiography (MRA) (1-6).

The progression of a UIA has been defined as unstable (7) and is associated with a higher rupture risk (1-6). Thus, determining the risk factors for UIA progression would be of substantial clinical value. Many previous studies have investigated the risk factors for IA progression (2,4,6,8-20). However, the results are not consistent. Juvela et al. indicated that women and cigarette smokers are at increased risk for IA progression (10); however, So et al. showed that IA progression was not positively correlated with female sex or cigarette smoking but was significantly associated with a history of excessive alcohol consumption (12). Backes et al. found that the PHASES [population, hypertension, age, size, earlier subarachnoid hemorrhage (SAH), site] and ELAPSS (earlier SAH, location, age $>60$ years, population, size, shape) scores were associated with IA progression $(15,16)$. However, the PHASES score is a model that provides the absolute risk of rupture for IAs, which is not very suitable for the prediction of IA growth (17). Recently, two studies confirmed the validation of the ELAPSS score for the prediction of UIA progression $(18,20)$. However, it is not clear whether this score has predictive value for UIAs in the Chinese population. Hence, we sought to determine what risk factors are related to progression in UIAs and to identify whether the ELAPSS score is able to predict IA progression in the Chinese population.

\section{Methods}

\section{Patients}

The study was conducted in accordance with the Declaration of Helsinki (as revised in 2013). This retrospective study was approved by our institutional ethics committee, and the requirement for informed consent was waived. From August 2011 through November 2019, 438 consecutive patients with UIAs were followed-up and reviewed. The reasons for patients not undergoing treatment included the following:
(I) patients refused; (II) patients had other serious diseases; and (III) patients had small IAs $(<5 \mathrm{~mm})$. The exclusion criteria included the following: (I) mycotic, traumatic or fusiform IAs or associated arteriovenous malformations or poor image quality; (II) loss to follow-up; (III) IAs treated before the next examination; and (IV) for nonprogressive IAs, an interval time between the first and last image scans less than 3 months. The follow-up endpoints were as follows: (I) failure to return for a follow-up visit (e.g., died) or refusal of further follow-up; (II) IAs were treated; (III) IA progression (grew or ruptured) or (IV) December 2020. For UIAs, follow-up images of the IAs were used to determine whether the IA grew. For ruptured IAs, the IA was assessed by the information at the last outpatient department visit or by a telephone survey. The follow-up periods were calculated from the date of the first images until the last day of the follow-up and expressed using the IA-month method.

Patients' electronic medical records were reviewed by one of the assessors, and the patients' clinical data including sex and age were collected. In addition, the following factors were recorded as either present or absent: hypertension, heart disease, diabetes mellitus, cerebral atherosclerosis, current alcohol consumption, current smoking, multiple IAs and history of SAH from other IAs.

\section{Image analysis}

CTA was performed on a 64-slice LightSpeed VCT machine (GE Healthcare, Milwaukee, WI, USA), and MRA was conducted on a 3.0-T clinical MRI system (Signa, GE Medical System, Milwaukee, WI, USA). The images were transferred to the GE Advantix workstation (Advantage Windows 4.5 ) to generate $3 \mathrm{D}$ volume renderings (VRs) and maximum intensity projections (MIPs). Two observers (one with 8-year experience in vascular imaging and the other with 18 years of experience in neuroradiology) analyzed the images independently. The IA location was divided into 5 categories according to the ELAPSS score: internal carotid artery (ICA), middle cerebral artery (MCA), anterior cerebral arteries (ACA, including the anterior cerebral artery and pericallosal artery), anterior communicating artery (ACoM), posterior communicating artery (PCoA), and posterior circulation arteries (PCA, including the vertebral artery, basilar artery, cerebellar arteries, and posterior cerebral artery). The IA shape (simple or irregular: an IA with a lobular or daughter sac was defined as having an irregular shape), the IA origin (sidewall or bifurcation), the IA size (maximum size, neck width, 

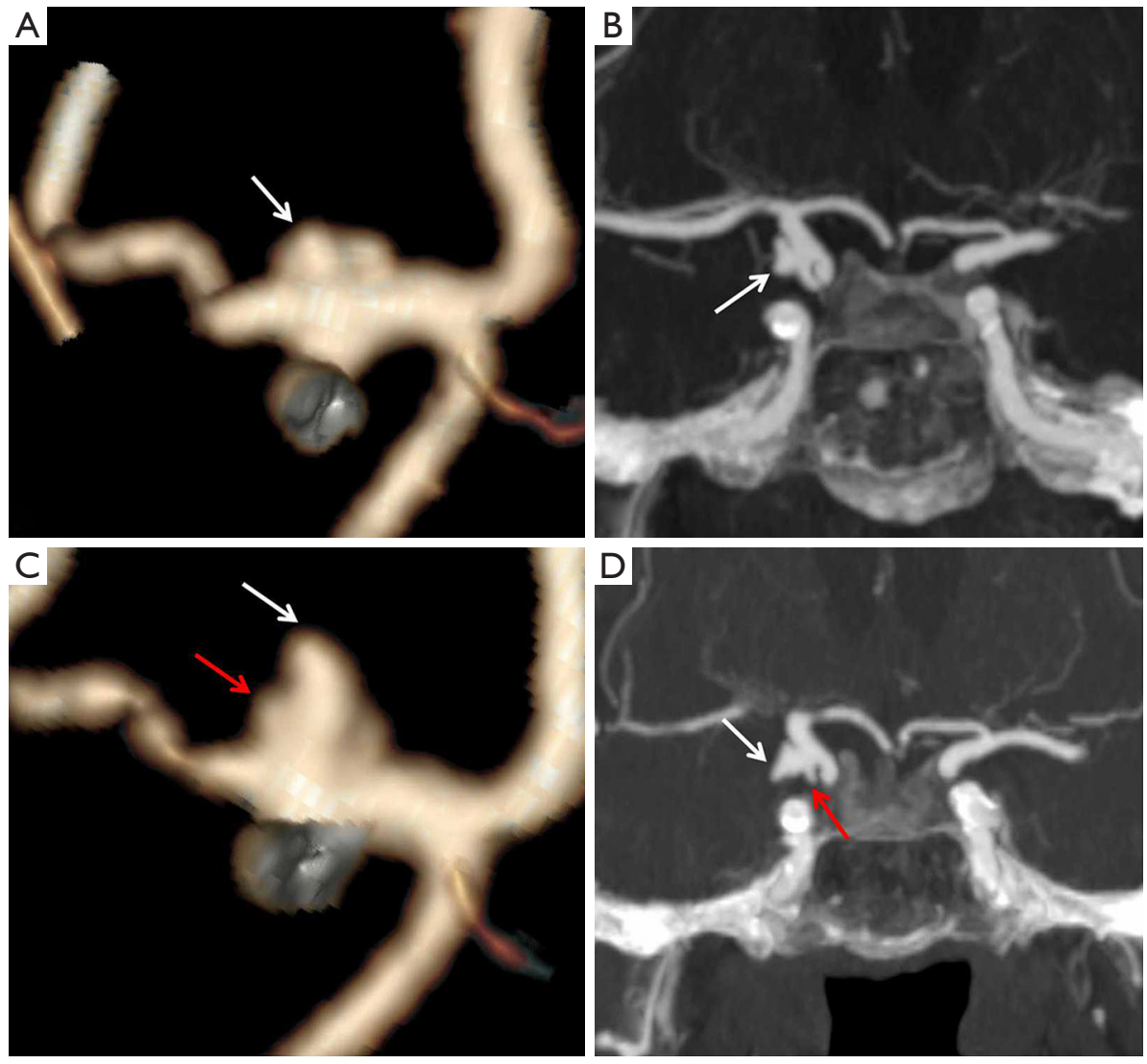

Figure 1 An 84-year-old woman had a history of hypertension and cerebral atherosclerosis. 3D volume rendering (VR) (A) and maximum intensity projection (MIP) (B) by computed tomography angiography (CTA) show that a right posterior communicating artery aneurysm with an irregular shape and a maximum size of $5.8 \mathrm{~mm}$ was found incidentally (arrow). The IA did not change after $23.6 \mathrm{months}$ of followup. However, 35.2 months later, the IA was enlarged and had a more irregular shape on repeated 3D VR (C) and MIP (D). The white arrow shows enlargement of the aneurysm, and the red arrow shows a daughter sac.

depth, and width), the flow angle (FA), and the parent vessel diameter (PD) were recorded. Furthermore, four secondary geometric indices the aspect ratio (AR, depth/ neck width), size ratio (SR, depth/parent vessel diameter), depth width ratio (DW, depth/width) and bottleneck factor (BF, width/neck width), were calculated. These variables have been identified and described in our previous studies $(21,22)$. The continuous data were calculated as average values, while any discrepancies in categorical data were reevaluated by a third reader (who had 25 years of experience in neuroradiology) for subsequent statistical analyses. Subsequently, these IAs were classified as nonprogressive or progressive IAs. Progressive IA was defined as IA ruptured or follow-up images that revealed a change in shape (such as the formation of blebs and lobes) or if there was an increase in the maximum size to $\geq 1 \mathrm{~mm}$ (Figure 1).

\section{ELAPSS score}

Backes et al. (15) introduced that the ELAPSS score for the prediction of IA progression. The ELAPSS score was also calculated for each IA in this study.

\section{Statistical analysis}

Statistics were performed with SPSS 17.0 (SPSS Inc., Chicago, Illinois, USA), and a $\mathrm{P}$ value $<0.05$ was regarded as statistically significant. Categorical data and continuous data are presented as the $\mathrm{n}(\%)$ and mean \pm standard deviation (SD), respectively. Categorical data and continuous data were compared using Fisher's exact tests and MannWhitney $\mathrm{U}$ tests, respectively. The features $(\mathrm{P}<0.2)$ in the univariate analysis were entered into a Cox proportional hazards regression model to calculate the independent risk 
Table 1 The clinical characteristics of patients with aneurysms

\begin{tabular}{|c|c|c|c|}
\hline Clinical data & Non-progression $(n=370)$ & Progression $(n=68)$ & $\mathrm{P}$ \\
\hline Age (years) & $58.48 \pm 11.11$ & $60.44 \pm 11.27$ & 0.183 \\
\hline$\leq 60$ years & $201(54.3 \%)$ & $30(44.1 \%)$ & 0.146 \\
\hline$>60$ years & $169(45.7 \%)$ & $38(55.9 \%)$ & \\
\hline Heart disease & $32(8.6 \%)$ & $4(5.9 \%)$ & 0.631 \\
\hline Diabetes mellitus & $40(10.8 \%)$ & $4(5.9 \%)$ & 0.275 \\
\hline Cerebral atherosclerosis & $120(32.4 \%)$ & $28(41.2 \%)$ & 0.166 \\
\hline Current alcohol & $65(17.6 \%)$ & $11(16.2 \%)$ & 0.863 \\
\hline History of SAH & $6(1.6 \%)$ & $1(1.5 \%)$ & 1.000 \\
\hline
\end{tabular}

$\mathrm{SAH}$, subarachnoid hemorrhage.

factors associated with the progression of IAs. The factors that have collinearity did not enter into the regression analysis at the same time. Receiver operating characteristic (ROC) curve analysis was performed to determine the cutoff value at which the value of (sensitivity + specificity -1) reached its maximum. The diagnostic accuracy of the risk factor score and the ELAPSS score was compared using ROC curve analysis.

\section{Results}

The clinical characteristics of the patients with IAs are listed in Table 1. A total of 438 patients with 491 UIAs were enrolled during the follow-up period of $25.4 \pm 20.32$ months (range, 0.2-102.4 months). Interobserver agreement for the IA progression categorization was excellent $(\kappa=0.890)$. IA progression was observed in 68 patients $(15.5 \%, 26$ men and 42 women). The mean age was 58.86 years for all patients: 58.67 years for males and 58.97 years for females. The two groups had no differences in terms of patients' clinical factors.

Table 2 summarizes the morphological characteristics of the IAs. IA progression occurred in 72 of 491 IAs (14.7\%). Most IAs were located in the ICA, originated from the sidewall and had a regular shape. The mean size of all IAs was $4.7 \pm 2.27 \mathrm{~mm}$ (range, 1.6-28.9 mm). IAs located in the ACoA, PCoA and ICA; located at the bifurcation; or having an irregular shape, neck width, depth, width, maximum size,
$\mathrm{FA}, \mathrm{PD}, \mathrm{AR}, \mathrm{SR}$ and $\mathrm{BF}$ were associated with progression risk. Forty-eight IAs had grown in size, 16 IAs had grown in size and changed in shape, 1 IA had changed in shape, and 7 IAs ruptured. Four patients with ruptured IAs were followed-up by telephone, and images could not be obtained. One IA had grown in size and changed in shape before rupturing, one IA had grown in size before rupturing, and another ruptured IA did not change in size or shape.

All of the variables described above $(\mathrm{P} \leq 0.2)$ were entered into a Cox proportional hazards regression model. IAs located at the bifurcation, with an irregular shape and with a high AR, tended to progress (Table 3). The cutoff value of the AR for IA progression was 0.83 .

According to the $\beta$ values of location at the bifurcation, irregular shape and high AR variables, a predictive scoring model for IA progression risk was established. For patients with an IA located at the bifurcation $(\beta=0.955)$, with an irregular shape $(\beta=1.092)$, and with an $\mathrm{AR} \geq 0.83 \quad(\beta=0.888)$, the score $=1$; otherwise, the score $=0$. Then, a predictive score ranging from 0 to 3 points was calculated. The ELAPSS score was applied and different risk classifications for IAs were calculated, as shown in Table 4 (15). The diagnostic accuracy of the area under the curve (AUC) for our predictive score and the ELAPSS score was 0.756 and 0.711 , respectively (Figure 2). The optimal cutoff values of our predictive score and that of the ELAPSS score were 0.5 and 11.5 , respectively; the sensitivity and specificity for 
Table 2 The morphological characteristics of aneurysms

\begin{tabular}{|c|c|c|c|}
\hline Morphologic parameters & Non-progression $(n=419)$ & Progression ( $n=72)$ & $P$ \\
\hline \multicolumn{4}{|l|}{ Location } \\
\hline ACoA & $38(9.1 \%)$ & $13(18.1 \%)$ & 0.034 \\
\hline ACA & $17(4.1 \%)$ & $2(2.8 \%)$ & 1.000 \\
\hline MCA & $41(9.8 \%)$ & $13(18.1 \%)$ & 0.063 \\
\hline ICA & $282(67.3 \%)$ & $32(44.4 \%)$ & $<0.001$ \\
\hline PCA & $16(3.8 \%)$ & $2(2.8 \%)$ & 1.000 \\
\hline Bifurcation & $88(21.0 \%)$ & $39(54.2 \%)$ & $<0.001$ \\
\hline Irregular shape & $28(6.3 \%)$ & $26(30.0 \%)$ & $<0.001$ \\
\hline $3.0-4.9 \mathrm{~mm}$ & $257(61.3 \%)$ & $27(37.5 \%)$ & $<0.001$ \\
\hline $5.0-6.9 \mathrm{~mm}$ & $83(19.8 \%)$ & $26(36.1 \%)$ & 0.003 \\
\hline $7.0-9.9 \mathrm{~mm}$ & $26(6.2 \%)$ & $11(15.3 \%)$ & 0.013 \\
\hline$\geq 10.0 \mathrm{~mm}$ & $6(1.4 \%)$ & $5(6.9 \%)$ & 0.013 \\
\hline Depth (mm) & $3.35 \pm 1.42$ & $4.98 \pm 3.72$ & $<0.001$ \\
\hline Width (mm) & $3.56 \pm 1.47$ & $5.34 \pm 4.36$ & 0.001 \\
\hline Neck width (mm) & $3.90 \pm 1.21$ & $4.57 \pm 1.75$ & 0.002 \\
\hline $\mathrm{PD}(\mathrm{mm})$ & $3.63 \pm 0.87$ & $3.35 \pm 0.76$ & 0.012 \\
\hline Follow-up time (months) & $32.01 \pm 22.60$ & $24.2 \pm 19.68$ & --- \\
\hline
\end{tabular}

$\mathrm{ACOA}$, anterior communicating artery; $\mathrm{ACA}$, anterior cerebral artery; $\mathrm{MCA}$, middle cerebral artery; PCoA, posterior communicating artery; ICA, internal carotid artery; PCA, posterior cerebral circulation; PD, parent vessel diameter; AR, aspect ratio; SR, size ratio; BF, width/neck width; DW, depth width ratio.

Table 3 Cox proportional hazards regression analysis for aneurysms progression

\begin{tabular}{lcccc}
\hline Variable & Odds ratio & $\mathrm{P}$ & $95 \% \mathrm{Cl}$ & $\beta$ \\
\hline Bifurcation & 2.600 & $<0.001$ & $1.607-4.207$ & 0.955 \\
Irregular shape & 2.981 & $<0.001$ & $1.753-5.068$ & 1.092 \\
Aspect ratio & 2.430 & 0.001 & $1.438-4.104$ & 0.888 \\
\hline
\end{tabular}

$\mathrm{Cl}$, confidence intervals; $\beta$, partial regression coefficient. 
Table 4 Application of ELAPSS score in this study

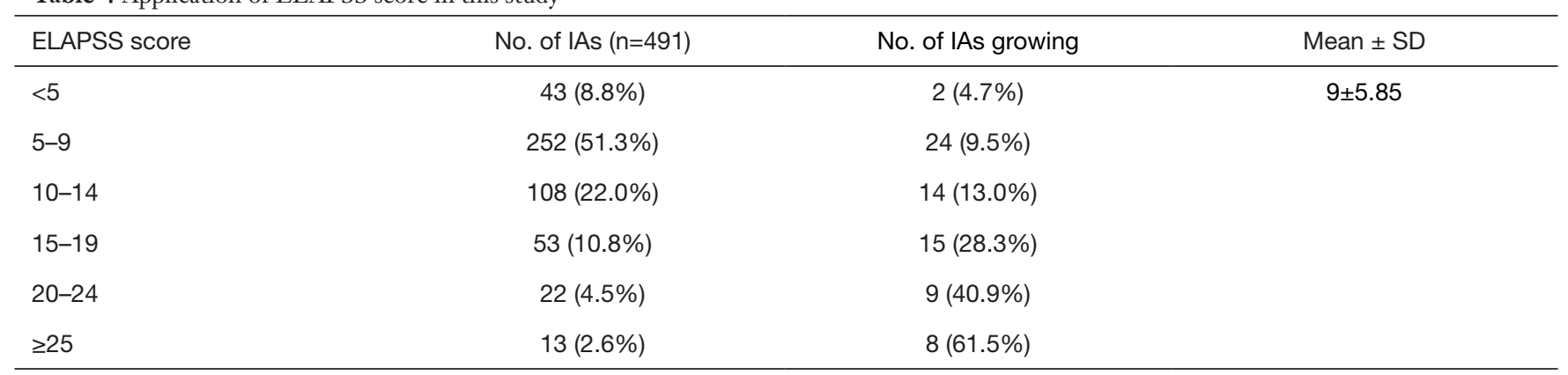

ELAPSS, Earlier subarachnoid hemorrhage, IA Location, Age, Population, IA Size and Shape.

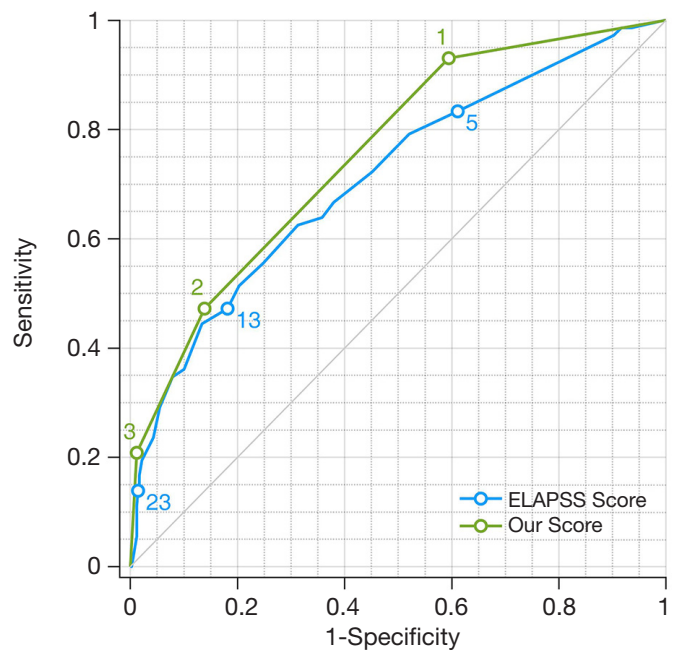

Figure 2 ROC curve showing the diagnostic accuracy of our predictive score and the ELAPSS score for the prediction of intracranial aneurysm progression. ROC, receiver operating characteristic; ELAPSS, Earlier subarachnoid hemorrhage, IA Location, Age, Population, IA Size and Shape.

the detection of progressive IAs were $93.1 \%$ and $40.6 \%$ for our predictive score and $55.6 \%$ and $75.2 \%$ for the ELAPSS score. The incidence of IA progression based on our predictive score in the low-risk group (score $=0$ ) and the high-risk group (score $\geq 1$ ) were $2.9 \%$ and $21.2 \%$, respectively, and those based on the ELAPSS score (score $<12$ or $\geq 12$ ) were $9.2 \%$ and $27.8 \%$, respectively (Table 5 ).

\section{Discussion}

UIAs with evidence of growth are considered to have an increased risk of rupture. In this study, we found that IAs located at the bifurcation, with an irregular shape and having a high AR, tended to progress. According to our
Table 5 Incidence of aneurysm progression based on our predictive score and the ELAPSS score

\begin{tabular}{lcccc}
\hline Score & $\begin{array}{c}\text { Total } \\
(\mathrm{n})\end{array}$ & $\begin{array}{c}\text { IAs progression } \\
(\mathrm{n})\end{array}$ & Risk & $\begin{array}{c}\text { Incidence of } \\
\text { progression }\end{array}$ \\
\hline Our score & & & & \\
0 & 175 & 5 & Low & $2.9 \%$ \\
1 & 224 & 33 & High & $21.2 \%$ \\
2 & 72 & 19 & & \\
3 & 20 & 15 & & \\
ELAPSS score & & & & \\
$0-11$ & 347 & 32 & Low & $9.2 \%$ \\
$12-14$ & 56 & 8 & High & $27.8 \%$ \\
$15-19$ & 53 & 15 & & \\
$\geq 20$ & 35 & 17 & & \\
\hline
\end{tabular}

predictive score established by these three factors, the AUC value was 0.756 , which was slightly higher than the ELAPSS score (0.711).

According to past reports, IA progression rates vary widely. Inoue et al. followed 1325 UIAs using MRA, and the results showed that the progression rate was $1.35 \%(5)$. So et al. followed 285 UIAs using DSA and found that the progression rate was $33.3 \%$ (12). Juvela et al. followed 111 UIAs using DSA and CTA, and the results indicated that the progression rate was $45 \%$ (10). However, the progression rate was $14.7 \%$ in this study, which is consistent with most studies demonstrating that the progression rate of IA was approximately $10 \%(4,6,9,11,14-18)$. There are many reasons for these differences, including the usage of different examination methods, sample sizes, follow-up times, and populations, as well as differences in the patients' clinical symptoms, the original size of the IAs, and the 
different standards used for IA progression calculations.

Compared to sidewall IAs, bifurcation IAs are believed to be more prone to rupture because the walls of the bifurcation areas are weak and altered by hemodynamic stress changed (23). Some previous studies have reported that bifurcation UIAs were more likely to progress. Choi et al. (24) reported that in IA $<7 \mathrm{~mm}$, bifurcation type was the sole significant risk factor in terms of growth. Although incidental small paraclinoid UIAs $(\leq 5 \mathrm{~mm})$ have a relatively lower rupture and growth risk, Jeon et al. (25) indicated that arterial branch-related location was a significant predictive factor for UIA progression. Recently, Suzuki et al. showed that UIA $(<10 \mathrm{~mm})$ located at a bifurcation was a risk factor for rupture (26). These reports are also consistent with our study in that UIA located at a bifurcation was a risk factor for progression.

Many previous studies have defined irregular shape as an aneurysm with a daughter sac or a lobular shape $(21,22)$. IAs with an irregular shape are usually estimated to be associated with a higher risk of rupture $(3,22,27)$. This finding may be because daughter sacs have a thinner wall, increased local hemodynamic stress and an unstable blood flow pattern $(22,28)$. Our previous study also reported that unruptured IAs with an irregular shape tended to be unstable (29). Phan et al. provided follow-up data with MRA for 62 unruptured IAs and found that IAs with multiple lobes had an increased risk of progression (8), which coincides with the results of this study. Brinjikji et al. (13) and Backes et al. (14) used meta-analyses, and Backes et al. (15) developed a prediction model (ELAPSS score) for the progression of unruptured IAs; they all found several risk factors, including irregular shape, which also agrees with this study.

Traditionally, IAs with a larger size are believed to be more prone to rupture than smaller IAs. Many previous studies have also reported that IA size is a significant independent predictor of IA progression (7-9,11,13,15$18,25,30)$, although these different studies used various threshold values for size. However, some other studies reported that size is not a significant independent factor associated with IA progression $(4,6,10,12)$. Interestingly, Matsumoto et al. (4) showed that size is a significant risk factor associated with IA rupture but not growth. In this study, we also found that with a larger size, IA progression tended to increase, but there was no significant difference according to the statistical analysis. The reason may be that size is not an independent factor. Compared to maximum size, the AR, which includes the IA neck width, has been argued to predict ruptured IAs more reliably $(21,22)$. In this study, we found that IAs with a high AR were more likely to progress.

Although two studies showed that ELAPSS score was associated with IA growth $(18,20)$, the c-statistic was 0.72 in the development cohort at 3 and 5 years (20). Meanwhile, in a retrospective study of ruptured IAs, $45.5 \%$ of patients were classified as low or intermediate risk using the ELAPSS score (31). Compared with the ELAPSS score (15), patient age, SAH history, IA location and IA size were not associated with IA growth in this study. There could be multiple reasons for this. It is well known that Japanese and Finnish patients have a higher risk of IA rupture than patients from other geographic regions (32). However, Backes et al. had two conflicting conclusions in their own two studies, reporting that Japanese and Finnish patients had an increased risk of IA growth in a multicenter study (15) and a decreased risk according to their meta-analysis (14), suggesting that the inclusion of patients from different countries could lead to bias. Surprisingly, that a history of $\mathrm{SAH}$ and an IA location at the ACoM represent zero points, even though these two factors are believed to be associated with IA rupture risk (33). The AUC of the ELAPSS score was 0.711 , the sensitivity for the detection of progressive IAs was $55.6 \%$, and the negative predictive value was $90.8 \%$. These values were lower than those of our predictive score.

Other clinical factors, such as age $(13,15,16)$, female sex $(2,10,13,14,30)$, hypertension $(14,16)$, cigarette smoking $(10,13,14,18,19,30)$ and excessive alcohol consumption (12), are associated with IA progression. Furthermore, other studies have reported that these clinical factors are not risk factors for IA progression $(4,8,11,17)$, which is consistent with the results in this study. The reasons may be that there were differences in the inclusion and exclusion criteria, differences in region and ethnicity, and variations in the guidelines for preventive IA treatment in these studies.

This study has several limitations. First, because this was a retrospective, nonrandomized study, patient selection bias should be noted. Some patients with high-rupturerisk UIAs did not participate in the follow-up imaging. Patients' confounding clinical characteristics may have led to statistical bias. Most IAs are located in the ICA, and IAs in the ICA seldom rupture. Second, some IAs were treated before progression, which may underestimate the incidence of IA progression. Third, although the optimal follow-up interval is still uncertain, our follow-up time needs to be extended. Some IAs may progress in the future. A prospective, multicenter and long-term follow-up design would be desirable in future studies. 
In conclusion, the present study demonstrates that UIAs located at the bifurcation, with an irregular shape and having a high AR may have an increased risk of progression in the Chinese population. Our predictive scoring model is of great value in predicting the progression risk of UIAs based on these three factors, and in clinical practice, more attention should be paid to UIAs when the risk score is $\geq 0.5$.

\section{Acknowledgments}

Funding: This study was supported by the Joint Project of Science and Health of Chongqing City, China (2021MSXM030) and the Miaopu Foundation of Third Military Medical University (2019R064).

\section{Footnote}

Conflicts of Interest: All authors have completed the ICMJE uniform disclosure form (available at http://dx.doi. org/10.21037/qims-21-32). The authors have no conflicts of interest to declare.

Ethical Statement: The authors are accountable for all aspects of the work in ensuring that questions related to the accuracy or integrity of any part of the work are appropriately investigated and resolved. The study was conducted in accordance with the Declaration of Helsinki (as revised in 2013). This retrospective study was approved by our institutional ethics committee (Xinqiao Hospital, 2016031), and the requirement for informed consent was waived.

Open Access Statement: This is an Open Access article distributed in accordance with the Creative Commons Attribution-NonCommercial-NoDerivs 4.0 International License (CC BY-NC-ND 4.0), which permits the noncommercial replication and distribution of the article with the strict proviso that no changes or edits are made and the original work is properly cited (including links to both the formal publication through the relevant DOI and the license). See: https://creativecommons.org/licenses/by-nc-nd/4.0/.

\section{References}

1. Villablanca JP, Duckwiler GR, Jahan R, Tateshima S, Martin NA, Frazee J, Gonzalez NR, Sayre J, Vinuela FV. Natural history of asymptomatic unruptured cerebral aneurysms evaluated at CT angiography: growth and rupture incidence and correlation with epidemiologic risk factors. Radiology 2013;269:258-65.

2. Kubo Y, Koji T, Kashimura H, Otawara Y, Ogawa A, Ogasawara K. Female sex as a risk factor for the growth of asymptomatic unruptured cerebral saccular aneurysms in elderly patients. J Neurosurg 2014;121:599-604.

3. Mehan WA Jr, Romero JM, Hirsch JA, Sabbag DJ, Gonzalez RG, Heit JJ, Schaefer PW. Unruptured intracranial aneurysms conservatively followed with serial CT angiography: could morphology and growth predict rupture? J Neurointerv Surg 2014;6:761-6.

4. Matsumoto K, Oshino S, Sasaki M, Tsuruzono K, Taketsuna S, Yoshimine T. Incidence of growth and rupture of unruptured intracranial aneurysms followed by serial MRA. Acta Neurochir (Wien) 2013;155:211-6.

5. Inoue T, Shimizu H, Fujimura M, Saito A, Tominaga T. Annual rupture risk of growing unruptured cerebral aneurysms detected by magnetic resonance angiography. $\mathrm{J}$ Neurosurg 2012;117:20-5.

6. Chien A, Liang F, Sayre J, Salamon N, Villablanca P, Viñuela F. Enlargement of small, asymptomatic, unruptured intracranial aneurysms in patients with no history of subarachnoid hemorrhage: the different factors related to the growth of single and multiple aneurysms. J Neurosurg 2013;119:190-7.

7. Brinjikji W, Chung BJ, Jimenez C, Putman C, Kallmes DF, Cebral JR. Hemodynamic differences between unstable and stable unruptured aneurysms independent of size and location: a pilot study. J Neurointerv Surg 2017;9:376-80.

8. Phan TG, Huston J 3rd, Brown RD Jr, Wiebers DO, Piepgras DG. Intracranial saccular aneurysm enlargement determined using serial magnetic resonance angiography. J Neurosurg 2002;97:1023-8.

9. Matsubara S, Hadeishi H, Suzuki A, Yasui N, Nishimura $\mathrm{H}$. Incidence and risk factors for the growth of unruptured cerebral aneurysms: observation using serial computerized tomography angiography. J Neurosurg 2004;101:908-14.

10. Juvela S, Poussa K, Porras M. Factors affecting formation and growth of intracranial aneurysms: a long-term followup study. Stroke 2001;32:485-91.

11. Burns JD, Huston J 3rd, Layton KF, Piepgras DG, Brown RD Jr. Intracranial aneurysm enlargement on serial magnetic resonance angiography: frequency and risk factors. Stroke 2009;40:406-11.

12. So TY, Dowling R, Mitchell PJ, Laidlaw J, Yan B. Risk of growth in unruptured intracranial aneurysms: a retrospective analysis. J Clin Neurosci 2010;17:29-33. 
13. Brinjikji W, Zhu YQ, Lanzino G, Cloft HJ, Murad MH, Wang Z, Kallmes DF. Risk Factors for Growth of Intracranial Aneurysms: A Systematic Review and MetaAnalysis. AJNR Am J Neuroradiol 2016;37:615-20.

14. Backes D, Rinkel GJ, Laban KG, Algra A, Vergouwen MD. Patient- and aneurysm-specific risk factors for intracranial aneurysm growth: a systematic review and meta-analysis. Stroke 2016;47:951-7.

15. Backes D, Rinkel GJ, Greving JP, Velthuis BK, Murayama Y, Takao H, Ishibashi T, Igase M, terBrugge KG, Agid R, Jääskeläinen JE, Lindgren AE, Koivisto T, von Und Zu Fraunberg M, Matsubara S, Moroi J, Wong GKC, Abrigo JM, Igase K, Matsumoto K, Wermer MJH, van Walderveen MAA, Algra A, Vergouwen MDI. ELAPSS score for prediction of risk of growth of unruptured intracranial aneurysms. Neurology 2017;88:1600-6.

16. Backes D, Vergouwen MD, Tiel Groenestege AT, Bor AS, Velthuis BK, Greving JP, Algra A, Wermer MJ, van Walderveen MA, terBrugge KG, Agid R, Rinkel GJ. PHASES score for prediction of intracranial aneurysm growth. Stroke 2015;46:1221-6.

17. Björkman J, Frösen J, Tähtinen O, Huttunen T, Huttunen J, Kurki MI, von Und Zu Fraunberg M, Koivisto T, Manninen H, Jääskeläinen JE, Lindgren AE. Aneurysm Size is the Strongest Risk Factor for Intracranial Aneurysm Growth in the Eastern Finnish Population. Neurosurgery 2019;84:1098-103.

18. Brinjikji W, Pereira VM, Khumtong R, Kostensky A, Tymianski M, Krings T, Radovanovich I. PHASES and ELAPSS Scores Are Associated with Aneurysm Growth: A Study of 431 Unruptured Intracranial Aneurysms. World Neurosurg 2018;114:e425-32.

19. Juvela S. Growth and rupture of unruptured intracranial aneurysms. J Neurosurg 2018;131:843-51.

20. Sánchez van Kammen M, Greving JP, Kuroda S, Kashiwazaki D, Morita A, Shiokawa Y, Kimura T, Kimura T, Cognard C, Januel AC, Lindgren A, Koivisto T, Jääskeläinen JE, Ronkainen A, Pyysalo L, Öhman J, Rahi M, Kuhmonen J, Rinne J, Leemans EL, Majoie CB, Vandertop WP, Verbaan D, Roos YBWEM, Berg RVD, Boogaarts HD, Moudrous W, Wijngaard IRVD, Hove LT, Teo M, George EJS, Hackenberg KAM, Abdulazim A, Etminan N, Rinkel GJE, Vergouwen MDI. External Validation of the ELAPSS Score for Prediction of Unruptured Intracranial Aneurysm Growth Risk. J Stroke 2019;21:340-6.

21. Wang GX, Liu J, Chen YQ, Wen L, Yang MG, Gong MF, Zhang D. Morphological characteristics associated with the rupture risk of mirror posterior communicating artery aneurysms. J Neurointerv Surg 2018;10:995-8.

22. Wang GX, Wen L, Yang L, Zhang QC, Yin JB, Duan $\mathrm{CM}$, Zhang D. Risk factors for the rupture of intracranial aneurysms using CT angiography. World Neurosurgery 2018;110:e333-8.

23. Kang HG, Kim BJ, Lee J, Kim MJ, Kang DW, Kim JS, Kwon SU. Risk factors associated with the presence of unruptured intracranial aneurysms. Stroke 2015;46:3093-8.

24. Choi HH, Cho YD, Jeon JP, Yoo DH, Moon J, Lee J, Kang HS, Cho WS, Kim JE, Zhang L, Han MH. Growth of Untreated Unruptured Small-sized Aneurysms (<7 $\mathrm{mm})$ : Incidence and Related Factors. Clin Neuroradiol 2018;28:183-9.

25. Jeon JS, Ahn JH, Huh W, Son YJ, Bang JS, Kang HS, Sohn CH, Oh CW, Kwon OK, Kim JE. A retrospective analysis on the natural history of incidental small paraclinoid unruptured aneurysm. J Neurol Neurosurg Psychiatry 2014;85:289-94.

26. Suzuki T, Takao H, Rapaka S, Fujimura S, Ioan Nita C, Uchiyama Y, Ohno H, Otani K, Dahmani C, Mihalef V, Sharma P, Mohamed A, Redel T, Ishibashi T, Yamamoto M, Murayama Y. Rupture Risk of Small Unruptured Intracranial Aneurysms in Japanese Adults. Stroke 2020;51:641-3.

27. UCAS Japan Investigators, Morita A, Kirino T, Hashi K, Aoki N, Fukuhara S, Hashimoto N, Nakayama T, Sakai M, Teramoto A, Tominari S, Yoshimoto T. The natural course of unruptured cerebral aneurysms in a Japanese cohort. N Engl J Med 2012;366:2474-82.

28. Meng H, Feng Y, Woodward SH, Bendok BR, Hanel RA, Guterman LR, Hopkins LN. Mathematical model of the rupture mechanism of intracranial saccular aneurysms through daughter aneurysm formation and growth. Neurol Res 2005;27:459-65.

29. Wang GX, Gong MF, Wen L, Liu LL, Yin JB, Duan CM, Zhang D. Computed tomography angiography evaluation of risk factors for unstable intracranial aneurysms. World Neurosurg 2018;115:e27-32.

30. Sonobe M, Yamazaki T, Yonekura M, Kikuchi H. Small unruptured intracranial aneurysm verification study: SUAVe study, Japan. Stroke 2010;41:1969-77.

31. Sturiale CL, Stumpo V, Ricciardi L, Trevisi G, Valente I, D'Arrigo S, Latour K, Barbone P, Albanese A. Retrospective application of risk scores to ruptured intracranial aneurysms: would they have predicted the risk of bleeding? Neurosurg Rev 2021;44:1655-63.

32. Greving JP, Wermer MJ, Brown RD Jr, Morita A, Juvela 
S, Yonekura M, Ishibashi T, Torner JC, Nakayama T, Rinkel GJ, Algra A. Development of the PHASES score for prediction of risk of rupture of intracranial aneurysms: a pooled analysis of six prospective cohort studies. Lancet Neurol 2014;13:59-66.

Cite this article as: Wang GX, Liu LL, Yang Y, Wen L, Duan CM, Yin JB, Zhang D. Risk factors for the progression of unruptured intracranial aneurysms in patients followed by CT/ MR angiography. Quant Imaging Med Surg 2021;11(9):41154124. doi: 10.21037/qims-21-32
33. Murayama Y, Takao H, Ishibashi T, Saguchi T, Ebara M, Yuki I, Arakawa H, Irie K, Urashima M, Molyneux AJ. Risk Analysis of Unruptured Intracranial Aneurysms: Prospective 10-Year Cohort Study. Stroke. 2016;47:365-71. 